\title{
RANCANGAN APLIKASI TIMESHEET KUALITAS DATA REPORT DAN PERFORMANCE DI PT SIEMENS INDONESIA
}

\author{
Agustiar Jamalih $^{1}$, Maria Cleopatra ${ }^{2}$, Ari Irawan ${ }^{2}$ \\ Program Studi Teknik Informatika, Fakultas Teknik dan Ilmu Komputer, \\ Universitas Indraprasta PGRI \\ Jalan Raya Tengah No 80, Kelurahan Gedong, Pasar Rebo, Jakarta Timur \\ Thiar.ali87@gmail.com ${ }^{1}$, mariacleopatra1313@gmail.com ${ }^{2}$,ari_irawan@unindra.ac.id ${ }^{3}$
}

\begin{abstract}
Abstrak
Perangkat lunak merupakan hal yang sering dilakukan dan menjadi hal terpenting di dalam proses penyelesaian sebuah penelitian informatika. Tahapan demi tahapan proses pengerjaan perangkat lunak harus dapat dilakukan secara detail dan sesuai dengan target. Masalah yang dihadapi sistem yang berjalan kurang efisien dalam pecatatan waktu dan cacat dalam laporan. Tujuan dari penelitian ini adalah merancang sistem basis data timesheet pada PT Siemens Indonesia divisi EM DG SWS serta merancang aplikasi yang sesuai dengan kebutuhan perusahaan dan diharapkan dapat mengatasi permasalahan pencatatan kegiatan pekerjaan yang dihadapi PT Siemens Indonesia divisi EM DG SWS. Metode yang dilakukan adalah dengan Grounded Research, yaitu suatu metode penelitian yang berdasarkan generasi empiris, menetapkan konsep, membuktikan teori, mengembangkan teori, mengumpulkan dan analisis data dalam waktu yang bersamaan. Sedangkan untuk perancangan basis data menggunakan metode database lifecycle. Dari penelitian yang dilakukan, dihasilkan suatu Rancagan Aplikasi Timesheet Kualitas Data Report dan Performance di PT Siemens Indonesia divisi EM DG SWS yang dapat digunakan untuk meningkatkan kinerja karyawan karena data tersimpan dengan teratur, sehingga bisa diakses dengan mudah. Kesimpulan dari penelitian ini adalah membantu perusahaan dalam pengolahan manhour proyek-proyek yang sedang berjalan beserta timesheet karyawan untuk mengatasi permasalahan yang dihadapi oleh PT Siemens Indonesia divisi EM DG SWS.
\end{abstract}

Kata Kunci: Rancangan aplikasi, Timesheet, Kualitas Data Report, Performance, PT Siemens Indonesia

\begin{abstract}
Software is something that is often done and is the most important thing in the process of completing an informatics research. Step by step, the software processing process must be done in detail and according to the target. Problems faced by the system running less efficient in recording time and flaws in reports. The purpose of this research is to design a timesheet database system at PT Siemens Indonesia EM DG SWS division and to design an application according to company needs and is expected to solve the problems of recording work activities faced by PT Siemens Indonesia EM DG SWS division. The method used is Grounded Research, which is a research method based on empirical generation, establishing concepts, proving theories, developing theories, collect and analyze data at the same time. Meanwhile, the database design uses the lifecycle database method. From the research conducted, a Data Report Quality and Performance Timesheet Application Design at PT Siemens Indonesia EM DG SWS division can be used to improve employee performance because the data is stored regularly, so that it can be accessed easily. The conclusion of this study is to assist the company in processing timesheet projects in progress along with employee timesheets to solve the problems faced by PT Siemens Indonesia EM division DG SWS. produced a Timesheet Application Plan for Quality Data Report and Performance at PT Siemens Indonesia EM DG SWS division which can be used to improve employee performance because the data is stored regularly, so that it can be accessed easily. The conclusion of this study is to assist the company in processing timesheet projects in progress along with employee timesheets to solve the problems faced by PT Siemens Indonesia EM division DG SWS. produced a Timesheet Application Plan for Quality Data Report and Performance at PT Siemens Indonesia EM DG SWS division which can be used to improve employee performance because the data is stored regularly, so that it can be accessed easily. The conclusion of this research is to assist the company in processing timesheet projects in progress along with employee timesheets to solve the problems faced by PT Siemens Indonesia EM division DG SWS. .
\end{abstract}

Keywords: Application design, Timesheet, Data Quality Reports, Performance, PT Siemens Indonesia 


\section{PENDAHULUAN}

Perkembangan teknologi informasi pada zaman seperti sekarang ini berkembang sangat pesat kemajuannya, di era globalisasi saat ini telah memberikan banyak manfaat dalam kemajuan di berbagai aspek sosial. Penggunan teknologi oleh manusia dalam membantu menyelesaikan pekerjaan merupakan hal yang menjadi keharusan dalam kehidupan. Perkembangan teknologi ini juga harus di ikuti dengan perkembangan pada PT Siemens Indonesia divisi EM DG SWS.

Report suatu kegiatan pekerjaan merupakan suatu yang penting dalam sebuah proyek yang sedang berjalan di perusahan-perusahan sekarang ini. Oleh karena itu sebuah manhour dalam proyek harus terorganisir dengan baik agar tidak terjadi over budget atau kerugian dalam suatu proyek, dan juga pencatatan kegiatan pekerjaan setiap karyawan agar lebih produktif.

Setelah peneliti melakukan penelitian di PT Siemens Indonesia divisi EM DG SWS. Peneliti menemukan suatu masalah sistem yang disitu data dan penyimpanan suatu kegiatan pekerjaan setiap employee tidak valid dan kurang efektif. Karena sistem yang dipakai masih menggunakan Microsoft exel untuk mendata suatu kegiatan project yang berskala waktu yang lama. Jadi data jam kerja sebuah project jadi tidak valid, karena setiap employee memasukan data sebulan sekali, kadang mereka juga lupa dalam sebulan itu mengerjakan project yang mana saja. Dari penelitian yang peneliti lakukan serta menganalisis dan mengimplementasikan pendapat, maka peneliti dalam hal ini menyimpulkan membuat suatu sistem aplikasi yang dapat mempermudah employee dalam melakukan pendataan kegiatan pekerjaan sesuai project yang mereka sedang kerjakan. Peneliti membuat suatu aplikasi berbasis java yaitu timesheet. Timesheet adalah aplikasi pencatatan jam kerja untuk masing-masing employee yang bertujuan untuk mengetahui apa saja yang dilakukan employee saat jam kerja dan berapa waktu yang dihabiskan untuk mengerjakan pekerjaan tersebut.

Penelitian ini diharapkan memberi manfaat untuk meningkatkan efisiensi dan efektifitas dalam melakukan proses pengolahan data, membantu dan meningkatkan kinerja employee, khususnya dalam pendataan laporan. Mempermudah pengolahan data timesheet dan report-report yang tepat dan akurat. Serta dengan dirancangnya program aplikasi timesheet ini dapt menjadi acuan di masa yang akan datang.

\section{PENELITIAN RELEVAN}

Dalam mendapatkan hasil penelitian yang baik, selain melakukan penelitian secara langsung, peneliti juga melakukan kajian. Beberapa artikel yanenjadi acuan peneliti adalah.

Perancangan Sistem Informasi Kepegawaian Pada PT. Bakri karya Sarana Batam. Tujuan penelitian ini membuat informasi kepegawaian berbasis web agar terdapat sebuah penilaian pegawai lapangan dan penilaian kualitas dari klien (Astari et al., 2019)

Perancangan Sistem Informasi Project Management BSD Division Pada PT. Wahana Ciptasinatria Jakarta-Bekasi. Dari penelitian ini untuk merancang sebuah sistem yang informasi proyek management yang dapat mengatasi permasalahan yang dihadapi dalam proses pencatatan dan pengilahan data proyek (Baydhowi \& Apriliah, 2020)

Perancangan Absensi Karyawan Menggunakan Sidik Jari Berbasis Raspberry Pi. Sistem absensi ini dibuat agar pegawai lebih mudah dalam melakukan absensi (Setyawan dkk, 2019).

Rancangan Bangun Sistem Informasi Monitoring Perkembangan Proyek Berbasis Web (Studi kasus:PT. Inti Pratama Semesta). Hasil riset jurnal tersebut untuk membangun sistem informasi monitoring perkembangan proyek agar mempermudah manager dalam melakukan pemantauan perkembangan proyek (Aprisa \& Monalisa, 2015).

Penelitian menganalisa dan mengimplementasikan sistem pencatatan waktu kerja karyawan dan proyek, pengajuan cuti, pengajuan lembur, pengajuan proposal dan pencatatan revisi berkas kerja pada PT Rekayasa Engineering. hasil riset jurnal tersebut adalah bahwa dalam semua pemasalahan pencatatan waktu kerja karyawan menjadi lebih valid, semua laporan kegiatan waktu kerja karyawan menjadi lebih actual dan efisien (Sutoyo \& Marpaung, 2013).

Penelitian untuk mengurangi fungsionalitas yang tidak perlu dan memaksimalkan funsionalitas sistem (Parmonagan R togatorop, 2018).

Penelitian perancangan dan pembuatan aplikasi sistem absensi dan istirahat karyawan ini dihasilkan aplikasi absensi karyawan pada PT XYZ secara cepat dan akurat. Aplikasi absensi karyawan pada PT XYZ memberikan informasi tentang kedisplinan karyawan berdasarkan 
kesesuaian waktu absensi pada check in, check out dan waktu istirahat karyawan dengan jadwal yang telah dibuat. Perhitungan gaji karyawan juga bisa didapatkan secara otomatis sesuai dengan jam kerja masing-masing karyawan (Novianti \& Lestari, 2018).

Rancangan Bangun Sistem Informasi Monitoring Perkembangan Proyek Berbasis Web (Studi Kasus: PT. Inti Pratama Semesta). Permasalahan dalam proyek tidak dapat diketahui dengan cepat mengakibatkan proyek menjadi lambat (Aprisa, S. Monalisa).

Dari apa yang sudah peneliti baca di semua artikel jurnal tersebut. peneliti menyimpulkan persamaan sistem aplikasi timesheet yang peneliti buat dengan riset jurnal diatas yaitu me-record dan mencatat semua kegiatan dalam melakukan kegiatan pekerjaan. Perbedaan dari sistem yang peneliti buat ada laporan jam kerja setiap employee, jadi manager mengetahui dan menghitung jam kerja setiap proyek yang sedang dikerjakan.

\section{METODE PENELITIAN}

Metode penelitian yang peneliti gunakan adalah Grounded Research. Menurut (Sugiyono, 2013) Metode Grounded Research yaitu suatu metode penelitian yang berdasarkan generasi empiris, menetapkan konsep, membuktikan teori, mengembangkan teori, mengumpulkan dan analisis data dalam waktu yang bersamaan. Dalam riset ini data merupakan sumber teori atau teori berdasar data, sehingga pengumpulan data yang telah dilakukan akan mendapat data-data yang akurat. Dalam penelitian ini data merupakan sumber teori atau acuan dalam membuat suatu aplikasi. Berikut ini langkah-langkah dalam melakukan Grounded Research yaitu : Menentukan masalah yang ingin diselidiki, mengumpulkan data-data yang dibutuhkan, melakukan analisis dan memberikan penjelasan, dan membuat laporan. Metode pengumpulan data yang dilakukan oleh peneliti adalah sebagai berikut:

1. Studi Lapangan

Studi lapangan ini peneliti lakukan untuk melihat langsung terhadap penerapan sistem informasi timesheet dalam kegiatan karyawan PT Siemens Indonesia divisi EM DG SWS. Dalam studi lapangan ini dipergunakan teknik pengumpulan data antara lain dengan cara:

a. Wawancara

Menurut (Subagyo, 2004). Suatu kegiatan dilakukan untuk mendapatkan informasi secara langsung dengan mengungkapkan pertayaan-pertayaan pada para responden. Mengadakan tanya jawab untuk mendapatkan informasi yang tepat dari narasumber langsung yang dalam hal ini dilakukan kepada employee serta manager divisi EM DG SWS mengenai kondisi kendala timesheet baik dalam pengolalaan maupun penyimpanan data dan juga penyajiannya.

b. Observasi

Menurut (Bin Ladjamudin, 2013). Untuk mendapatkan gambaran yang jelas mengenai pelaksaan sistem yang berjalan serta mencari dan mengumpulkan data yang dibutuhkan langsung dari sumbernya, yaitu dengan pengamatan langsung terhadap penyeleksian news untuk melengkapi wawancara. Peneliti mengamati suatu objek, peristiwa, kondisi atau suasana kerja yang ada di PT Siemens Indonesia divisi EM DG SWS untuk menjawab pertanyaan penelitian. Dan juga mengamati dan mempelajari sistem yang ada sebelumnya yang sudah berjalan terutama kebutuhan kegitatan pekerjaan dengan meninjau kendala yang ada.

2. Studi Kepustakaan

Studi Kepustakaan yaitu mengumpulkan data yang diperoleh dari berbagai sumber buku di perpustakaan serta sumber-sumber lain sebagai penunjang dalam menyelesaikan penelitian ini. Studi pustaka dilakukan di perpustakaan Universitas Indraprasta PGRI, browsingmelalui search engine di internet, dan beberapa buku yang terkait dengan penelitian yang dilakukan peneliti. Dari bahan-bahan tersebut diambil teori-teori yang dapat dijadikan landasan untuk menganalisa masalah yang ditemukan dalam penelitian. Sehingga dapat memberikan hasil akhir yang maksimal.

\section{HASIL DAN PEMBAHASAN}

Pencatatan terhadap total waktu, pencatatan terhadap total peneluaran biaya, peringatan jika waktu dan pengeluaran yang diperkirakan telah melewati batas yang telah ditentukan, pencatatan terhadap 
proyek dan status proyek, pencatatan terhadap file proyek, dan hasil akhir laporan berupa exel dari SDM (Sutoyo \& Marpaung, 2013).

Proses bisnis sistem yang berjalan di PT Siemens Indonesia divisi EM DG SWS sebagai berikut:

1. Proses Pendataan Employee

Hasil data employee yang masuk dalam sistem Microsoft exel setiap bulannya. Dan dari data itu terlampir id employee, status employee, namaemployee, jabatan employee yang harus di isi setiap employee.

2. Proses Pendataan Project/workcode

Proses pendataan project disini ialah melakukan input nama-nama projectapa saja yang sedang dikerjakan oleh divisi Energy Management Digital Grid Software end Solution (EM DG SWS). danproject-project inilah yang akan menjadi jadwal engineer dalam melakukan pekerjaannya sela sebulan.

3. Proses Pengisian Timesheet

Proses pengisian timesheet disini ialah setiap employee berkewajiban mengisi semua kegiatan pekerjaan mereka selama sebulan, dari setiap pekerjaan yang mereka dapat dari project manager. Dan nantinya akan menjadi laporan timesheet di setiap project manager.

4. Laporan

Setelah semua emplooye sudah menyerahkan data timesheet mereka ke project manager, dari situ projectmanagerakan mengoreksi lagi apakah data timesheet tersebut sesuai dengan apa yang sudah di intruksikan kegiatan pekerjaan selama satu bulan. Setelah semua proses pengoreksian selesai project manager akan mengirimkan semua data timesheet ke manager untuk di report lagi sebagai data menhaour divisi itu ke HR.

Maka diambil kesimpulan dari permasalahan yang peneliti lakukan yaitu dengan memberikan ide untuk membuat aplikasi Perancangan Aplikasi Timesheet Kualitas Data Report dan Performance di PT Siemens Indonesia berbasis java. Agar mudah dalam penyimpanan data, pengolahan data dan penyajian datanya. Berikut ini gambaran sistem yang diusulkan di PT Siemens Indonesia dalam diagram konteks dan ERD (Entity Relationship Diagram).

\section{Diagram Konteks Sistem Berjalan}

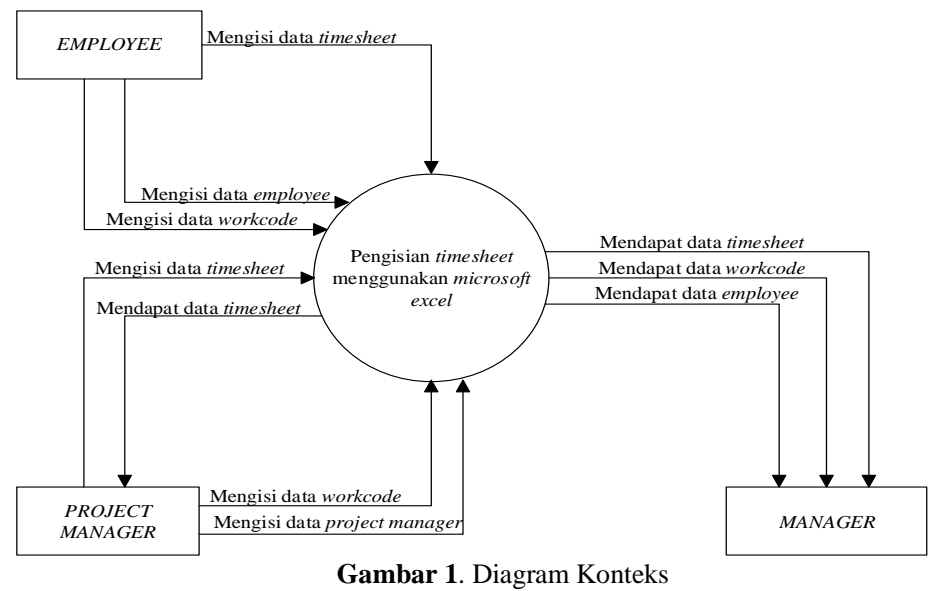

Diagram konteks sistem berjalan diatas memperlihatkan gambaran umum dari subsistem timesheet employee, karena seluruh subsistem hanya diwakili oleh satu symbol proses. Subsistem timesheet dengan kesatuan luar atau kelompok pengguna yaitu employee. Employee dapat mengisi data timesheet. Project manager menerima data timesheet dan meng-approve timesheet. Untuk manager hanya menerima seluruh data report timesheet yang ada pada sistem timesheet. 


\section{Diagram Konteks Sistem Usulan}

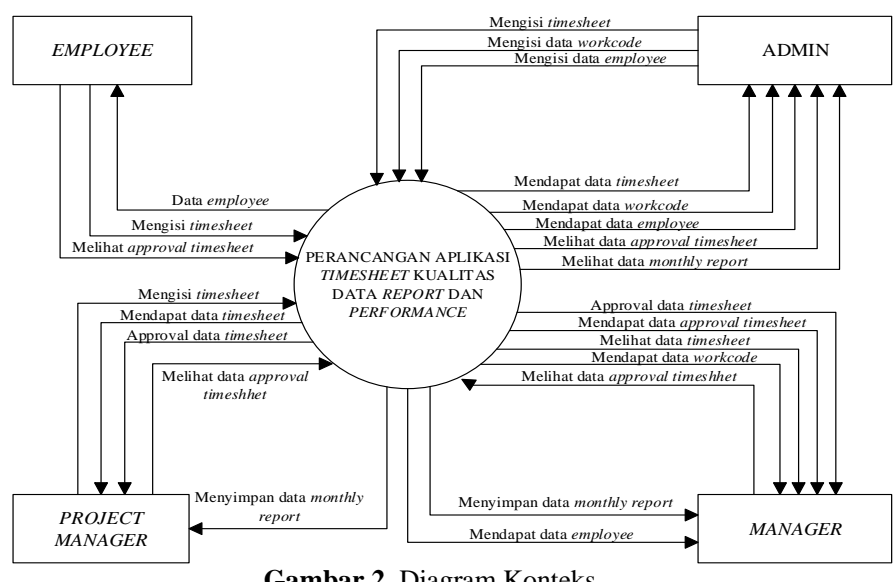

Diagram konteks diatas memperlihatkan gambaran umum dari subsistem timesheet employee, karena seluruh subsistem hanya diwakili oleh satu symbol proses. Subsistem timesheet dengan kesatuan luar atau kelompok pengguna yaitu admin. Manager atau admin dapat login dan mengakses semua data pada semua komponen. Karyawan dapat mengisi data timesheet. Project manager menerima data timesheet dan meng-approve timesheet. Untuk manager hanya menerima dan melihat seluruh data report timesheet yang ada pada sistem timesheet.

\section{Diagram Nol Sistem Usulan}

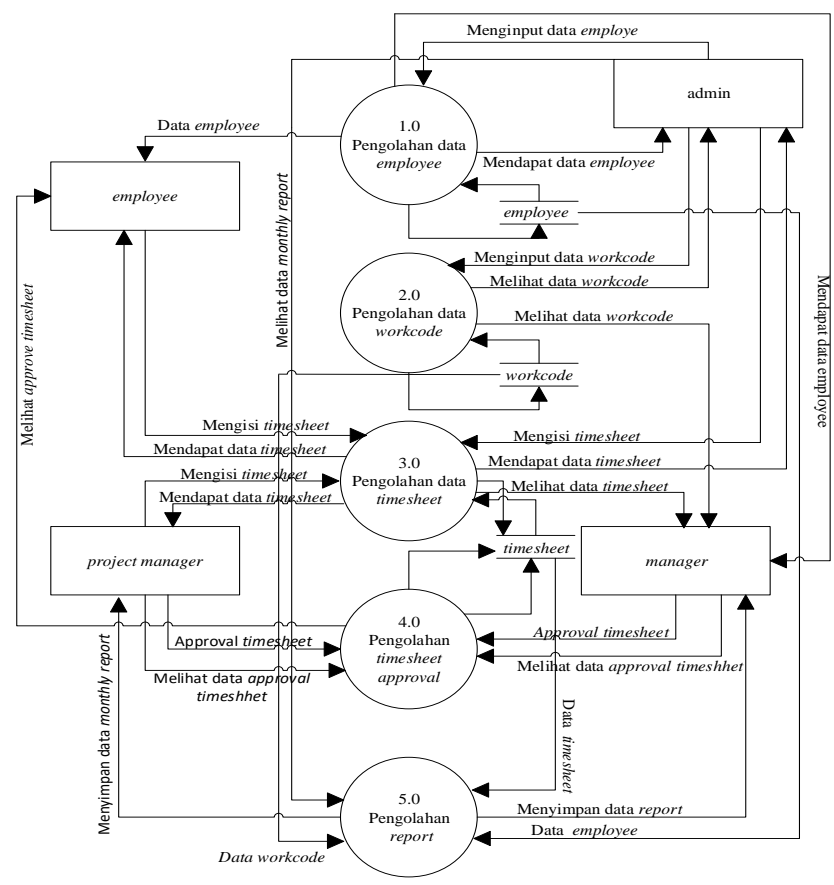

Gambar 3. Diagram Konteks

Diagram Nol diatas memperlihatkan proses-proses employee login dalam melakukan pengisian timesheet. Disitu admin dan manager dapat mengakses semua proses, project manager bisa melihat employee dalam melakukan kegiatan pekerjaan (timesheet) setiap harinya dan meng-approve timesheet yang sudah valid setiap bulannya. 


\section{Entity Relationship Diagram (ERD)}

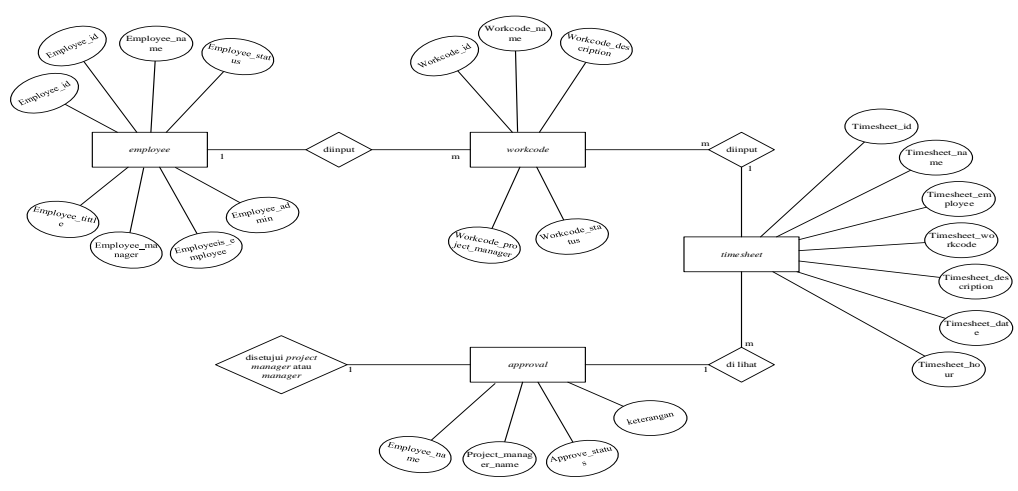

Gambar 4.Entity Relationship Diagram (ERD)

Pada gambar diatas dapat dijelaskan bahwa admin dapat mengakses semua entitas atau komponen. Admin dapat melakukan pendataan identitas employee dan timesheet employee. Report dilakukan dari data karyawan dan timesheet, yang nanti akan dibuat report bulanan berdasarkan semua kegiatan employee selama satu bulan.

\section{Tampilan Aplikasi}

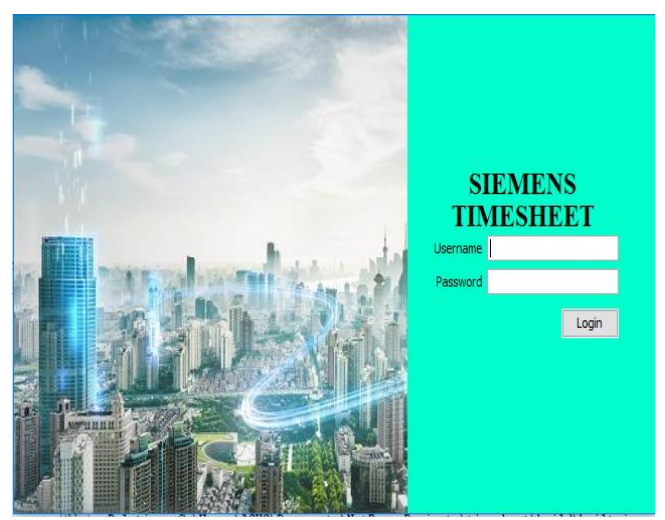

Gambar 5. Tampilan Form Login

Tampilan form login ini muncul di awal saat pengoprasian aplikasi timesheet untuk diisi oleh admin sebagai user. Masukan username dan password yang sesuai dengan hak akses employee yang sudah dibuatkan oleh admin, supaya bisa mengoprasikan aplikasi pengolahan timesheet employee. Jika username dan password sesuai, maka akan masuk tampilan Menu Utama.

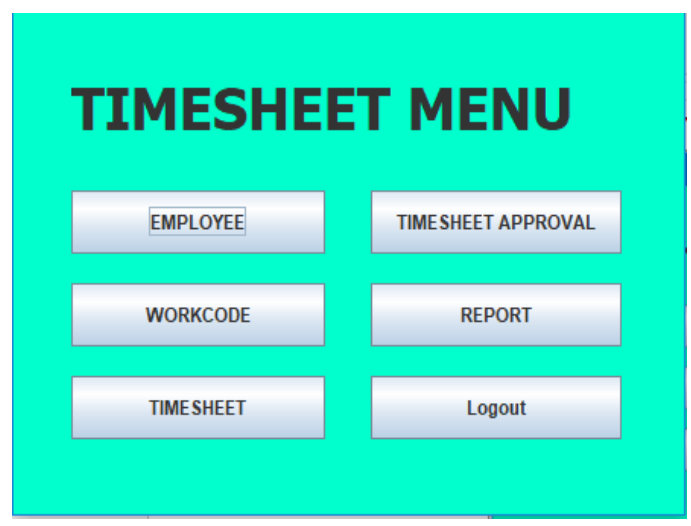

Gambar 6. Tampilan Menu Utama 
Tampilan diatas menu utama terdiri dari 5 Menu Bar diantaranya Data Employee, Data Workcode, Data Timesheet, Timesheet Approval, dan Report. Kelima menu ini hanya dapat di akses manager dan admin. Untuk project manager dan employee hanya dapat mengakses timesheet dan timesheet approval.

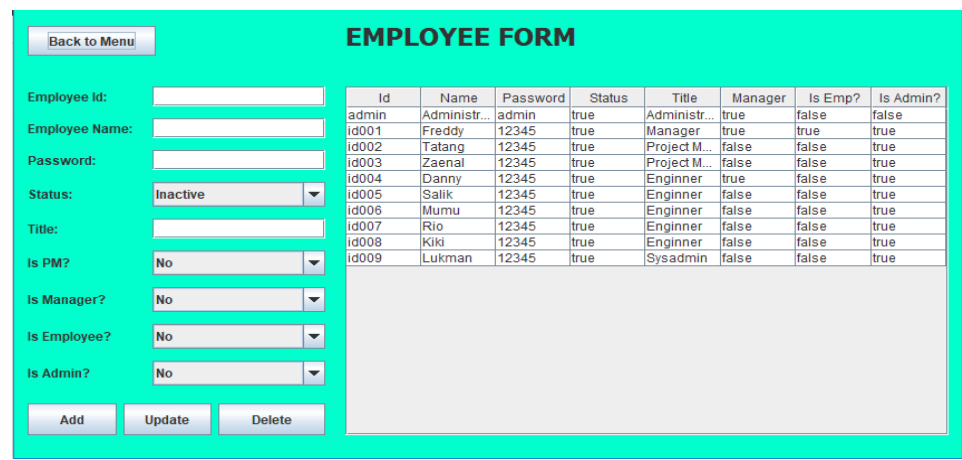

Gambar 7. Tampilan Employee Form

Tampilan diatas merupakan input data employee untuk di buatkan username dan password. Keseluruhannya hanya dapat di akses oleh admin dan manager. Form ini bisa menambah data employee, mengedit data employee dan menghapus data employee yang sudah tidak diperlukan lagi.

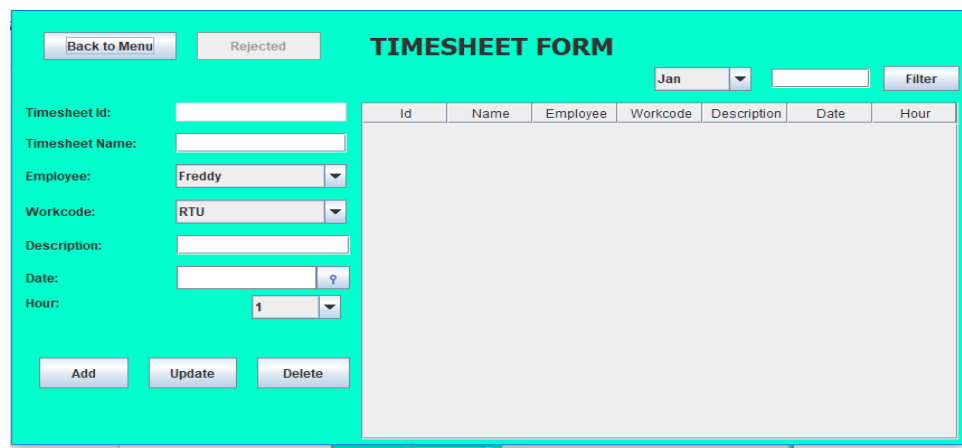

Gambar 8. Tampilan Timesheet Form

Tampilan diatas merupakan form untuk employee dalam pengisian timesheet. Form ini dapat di akses oleh employee, admin, project manager dan manager. Form ini bisa menambah data timesheet employee, mengedit data timesheet employee dan menghapus data timesheet employee yang sudah tidak diperlukan lagi.

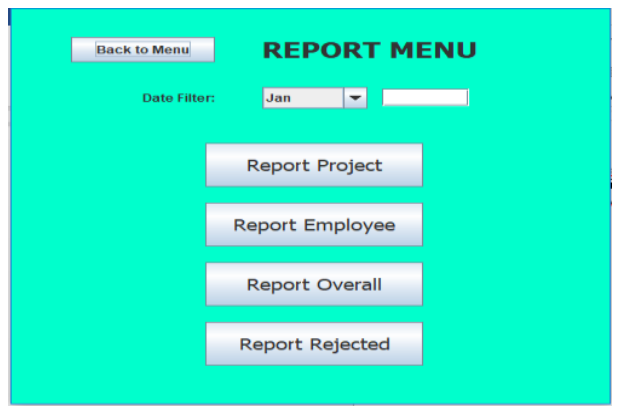

Gambar 9. Tampilan Report Menu

Tampilan diatas merupakan data report dari semua bulan dan tahun tertentu. Report ini terdiri dari beberapa menu yaitu Report Project, Report Employee, Report Overall dan Report Rejected. 


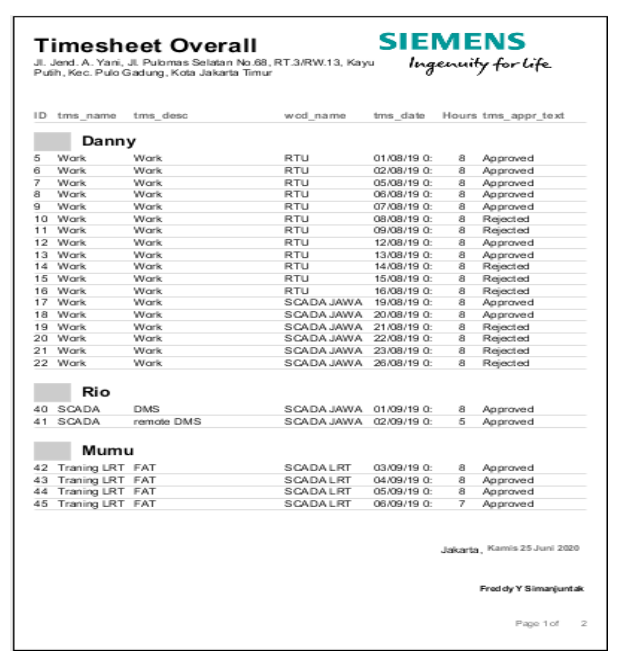

Gambar 10. Tampilan Report Timesheet Overall

Tampilan diatas merupakan rancangan form report keluaran dari seluruh timesheet employee yang sudah di approve dan di reject selama satu bulan. File ini akan disimpan oleh manager.

\section{SIMPULAN}

Berdasarkan pembahasan dari penelitian ini yang dilakukan oleh peneliti, peneliti menghasilkan sebuah sistem informasi untuk PT Siemens Indonesia Divisi EM DG SWS. Dengan adanya sistem informasi ini dapat menjadi solusi dari pemecahan masalah dalam pencatatan, pengolahan data project, meningkatkan kinerja dan mempermudah dalam manajemen data project, serta dengan adanya sistem informasi ini tentunya akan lebih mempermudah proses control dan pengawasan juga memudahkan membuat laporan yang setiap bulan.

\section{DAFTAR PUSTAKA}

Aprisa, \& Monalisa, S. (2015). Rancang Bangun Sistem Informasi Monitoring Perkembangan Proyek Berbasis Web (Studi Kasus: PT. Inti Pratama Semesta). Jurnal Rekayasa Dan Manajemen Sistem Informasi.

Astari, Z., Pibriana, D., \& Rusbandi, R. (2019). Perancangan Sistem Informasi Kepegawaian Pada PT. Bakri Karya Sarana Batam. JATISI (Jurnal Teknik Informatika Dan Sistem Informasi). https://doi.org/10.35957/jatisi.v5i2.148

Baydhowi, Muhamad; Apriliah, W. (2020). Sistem Informasi Project Management BSD Division Pada PT. Wahana Ciptasinatria Jakarta-Bekasi. Vol 4 No 2. http://www.ejournal-binainsani.ac.id/index.php/IMBI/article/view/1351

Bin Ladjamudin. (2013). Analisis dan Desain Sistem Informasi. Analisis Dan Desain Sistem Informasi. https://doi.org/10.1017/CBO9781107415324.004

Novianti, T., \& Lestari, G. S. (2018). Rancang Bangun Aplikasi Sistem Absensi Karyawan pada PT XYZ. Jurnal Komunika : Jurnal Komunikasi, Media Dan Informatika. https://doi.org/10.31504/komunika.v7i2.1676

Parmonagan R togatorop. (2018). Analisis Penerapan Open Source Enterprice Resources Planning Pada Proses Pengajuan Cuti Karyawan di Institut Teknologi Del (IT DEL).

Setyawan, Dedi; Kurniabudi, Kurniabudi; ASTRI, L. Y. (2019). Perancangan Absensi Karyawan Menggunakan Sidik Jari Berbasis Raspberry Pi (Studi Kasus : Kantor Dinas Pengendalian Penduduk Dan Kelurga Berencana Muaro Jambi). http://ejournal.stikom-db.ac.id/index.php/jimti/article/view/685

Subagyo, J. (2004). Metode Penelitian Dalam Teori Dan Praktek. In Rineka Cipta.

Sugiyono. (2013). Metode Penelitian Pendidikan Pendekatan Kuantitaif, Kualitatif, dan R\&DSugiyono. 2013. "Metode Penelitian Pendidikan Pendekatan Kuantitaif, Kualitatif, dan R\&D.” Metode Penelitian Pendidikan Pendekatan Kuantitaif, Kualitatif, dan R\&D. https://doi.org/10.1. In Metode Penelitian Pendidikan Pendekatan Kuantitaif, Kualitatif, dan $R \& D$. https://doi.org/10.1007/s13398-014-0173-7.2

Sutoyo, R., \& Marpaung, F. H. (2013). Analisis dan Perancangan Sistem Basis Data Catatan Waktu Kerja dan Proyek Karyawan pada PT Rekayasa Engineering. ComTech: Computer, Mathematics and Engineering Applications. https://doi.org/10.21512/comtech.v4i2.2540 